\title{
Exploração e Precarização do trabalho na Região Metropolitana de Salvador.
} (RMS).

\section{$\underline{\text { Rebeca Oliveira Santana }}+$; Jossel Borges dos Santos ${ }^{2}$.}

1. Bolsista PIBIC/Fapesb, Graduando em Ciências Econômicas, Universidade Estadual de Feira de Santana, email. rebeca.lauper@gmail.com.

2. Orientador, Departamento de Ciências Sociais Aplicadas, Universidade Estadual de Feira de Santana, email.josselborgessantos@gmail.com.

Palavras Chave: Precarização do trabalho, desigualdades sociais, políticas públicas.

\section{INTRODUÇÃO}

De acordo com a abertura comercial, e as transformações modernizantes pelo capital financeiro, ocorridas nos anos 90, através da globalização, e os efeitos das reformas neoliberais no mercado de trabalho. A classe trabalhadora passou a sentir os efeitos das precarizações nas condições de vida e de consumo que se estenderam até o período mais recente da economia brasileira. Para Druck (2011). A acumulação flexível de capital foi responsável por alterar o padrão de vida e trabalho das pessoas, inserido as precarizações como parte dos processos de financeirização na economia.

$\mathrm{O}$ desafio fundamental para muitos economistas contrários às reformas promovidas pelo Estado mínimo foi o papel de reorganizar a classe trabalhadora. Nesse sentido, os casos de exploração e precarizações tanto na formalidade, quanto nas informalidades dos mercados fazem parte da estrutura periférica dependente característica de uma economia subdesenvolvida e desigual, que expressam a superexploração da força de trabalho. No Brasil as denúncias referentes a essa realidade são registradas pelo $\mathrm{MTE}^{1}$, que cumpre o papel de regular e fiscalizar o mercado de trabalho. Segundo Antunes (2015), existem dois processos que condicionam a situação de precarização na vida do trabalhador. Se por um lado a baixa remuneração da força de trabalho que caracteriza o fluxo de capital estrangeiro produtivo constitui um fator obstaculizado do avanço tecnológico, pelo outro a "qualificação" da força de trabalho, como prega o discurso modernizador e flexível, resulta no aumento da superexploração da força de trabalho.

\footnotetext{
${ }^{1}$ Ministério Público do Trabalho e Emprego. Órgão administrativo do Governo Federal, responsável por fiscalizar e regulamentar as condições de trabalho na sociedade brasileira.
} 
Muito antes da divisão internacional do trabalho, a Bahia sempre apresentou na sua história, traços característicos de desigualdades, seja pelo processo de colonização, que definiu as classes sociais (Escravos, senhores de Engenho), seja mais tarde ao iniciar seu processo de industrialização regional, frente ao Sudeste do país já modernizado e industrializado. Para refletir sobre essa questão, é importante salientar que na história na industrialização da Bahia, ela sempre foi marcada pela característica de ser intensiva em trabalho, o que garantiu ser um elemento fundamental para manter as atividades econômicas do Estado e sua industrialização durante os anos 50². Todavia as mudanças que aconteceram no Estado baiano nos últimos anos, não diminuíram os níveis de concentração de renda, desigualdades sociais, e pobreza ainda presentes pela RMS.

Por essa razão torna se fundamental investigar as condições de precarização persistente pela Região Metropolitana da Bahia. No Governo Dilma, o mercado de trabalho apresentou uma pequena participação na contratação por carteiras assinadas, segundo os dados do IBGE para os anos de 2012, na região Metropolitana de Salvador tal crescimento aproximou a $73 \%$ da população, enquanto o crescimento da população ocupada foi de 2,2\% (de 22,5 para 23,0 milhões) no mesmo ano. Todavia, a informalidade persiste nas atividades comerciais baianas. No Governo do PT as políticas públicas garantiram assistência social, para as famílias que viviam sobre condições precárias, garantindo uma renda mínima a cada trabalhador urbano, abaixo da linha de pobreza. Todavia isso não erradicou a pobreza histórica e estrutural, característica elementar da condição dependente da economia baiana. Segundo Cavalcante (2008) “[...] a formulação de políticas públicas de desenvolvimento pressupõe o conhecimento da trajetória econômica e social e da própria história do país ou da região sobre a qual se pretende intervir".

\section{MATERIAL E MÉTODOS}

Essa pesquisa se caracteriza por uma análise teórica- empírica. Sendo necessário fazer uma revisão bibliográfica sobre o histórico do desenvolvimento econômico do Brasil e Bahia, reportando até os períodos mais recentes. Depois o

\footnotetext{
2 Almeida (2013) discute sobre as condições de integração regional da Bahia, e suas características frente a um centro nacional industrializado. Levando em consideração que São Paulo era intensivo em Capital, enquanto o Bahia intensivo em mão de obra. Essas discussões estão presentes no trabalho desenvolvido Rômulo Desenvolvimento Regional e Industrialização.
} 
recolhimento de macrodados, informações a respeito das condições da estrutura do mercado de trabalho, e as condições de desigualdades sociais pela Região metropolitana de Salvador na Bahia (RMS). Com isso as consultas foram feitas pelas fontes oficiais de informações, como, (SEI DIEESE, IPEADATA, PED, IBGE).

\section{RESULTADOS E/OU DISCUSSÃO (ou Análise e discussão dos resultados)}

Do ponto de vista teórico as características do desenvolvimento socioeconômico do Brasil e na Bahia, evidencia que os processos de industrialização aconteceram sem superação das desigualdades sociais. Nesse sentido observando as condições da estrutura do mercado de trabalho, os efeitos de precarização sobre a classe trabalhadora, que se expressam sobre as condições de vida, através da renda das famílias ainda é algo visível e doloso ao trabalhador. Em um recorte dos anos 90, na literatura econômica para essa temática os autores citados são: Druck, Antunes, e na Bahia para as discussões econômicas, dentre vários autores são: Rômulo Almeida, e Pinto Aguiar.

$\mathrm{Na}$ Bahia os dados comprovam o ambiente desigual e precário sobre a RMS nos últimos anos. O crescimento econômico auferido por algumas décadas não garantiu condições para eliminar as desigualdades da região, caso comprovado pelos indicadores sociais na Bahia, o comprova uma péssima posição no ranking do IDH dos municípios. De acordo com as pesquisas do PED- Pesquisa de Emprego e Desemprego, apresentadas pela SEI/ DIEESE (2014). O contingente de desempregados foi estimado em 325 mil pessoas, o de ocupados em 1.545 mil e a PEA em 1.870 mil. Mas a informalidade ainda persiste, o que se torna um problema socioeconômico e evidencia exploração e condições precárias sobre as famílias.

\section{CONSIDERAÇÕES FINAIS}

De acordo com as informações recolhidas ao longo deste trabalho, pode-se observar que as dificuldades para os trabalhadores baianos, são imensas, estão presentes na formalidade, mais, sobretudo na informalidade dos mercados, característica intrínseca da exploração e não superação da pobreza, dada as contradições de crescimento econômico e desenvolvimento humano. Isso comprova a condição de 
pobreza em que as populações estão submetidas, mas as faltas de políticas que possa enfrentar esses problemas. Durante o Governo do PT desenvolveu se como alternativa para superar esses problemas, as políticas de transferência de renda, minimiza os efeitos, mais não erradica a pobreza histórica imposta por anos na história desse país.

\section{REFERENCIAS}

ANTUNES, Ricardo. Riqueza e Miséria do Trabalho no Brasil, São Paulo. Ed. Boitempo, 2015.

AGUIAR, Pinto. Notas sobre o Enigma Bahiano, Salvador- Bahia. Ed. Progresso, 1958.

DIEESE, A Informalidade no Mercado de Trabalho da Bahia nos anos 2000. Salvador, 2013.

DRUCK, Graça. Trabalho, Precarização e Resistências: novos e velhos desafios? Salvador: Caderno CRH, 2011.

ESPÍNOLA MACÊDO, Gepherson; ZIMMERMAN, Clóvis. Programas Sociais no Brasil: Um Estudo sobre o Programa Bolsa Família no Interior do Nordeste brasileiro. Salvador: Caderno CRH; v. 28; n. 73, 2015.

FIEB, Rômulo Desenvolvimento Regional e Industrialização. Caderno Ed. SCI/FIEB. Salvador- Bahia 2013.

IBGE, Pesquisa Mensal de Emprego- Abril 2012. DISPONÍVEL In: http://www.ibge.gov.br/home/estatistica/indicadores/trabalhoerendimento/pme nova/Ev olucao emprego carteira trabalho assinada.pdf. 24 de Setembro, às 16:30.

MTE. Ministério do Trabalho em Emprego. Agenda Nacional do Trabalho Decente. Brasília, 2006.

PED, Pesquisa de Emprego e Desenvolvimento. Mercado de Trabalho na Região Metropolitana de Salvador em 2014. DISPONÍVEL In: http://www.sei.ba.gov.br/images/releases mensais/pdf/ped/ped estudos especiais/empr ego 2014.pdf. 24 de Setembro, às 17:51.

SANTOS DOS BORBA, Fernanda Ludiara. O Papel do Estado no Combate ao Trabalho Análogo ao de Escravo na Bahia. Salvador, 2011.

SANTOS, Jossel Borges. Terceirização, Crise e Acumulação de Capital: Seus Efeitos na COPENE em Camaçari- BA. Campina Grande: Dissertação de Mestrado, 1999 
